\title{
A Multi-Agent System for Management of Supplier Selection Process in a Fuzzy Supply Chain
}

\author{
Vivek Kumar \\ Research Scholar \\ Suresh Gyan Vihar University \\ Jaipur 3032004 \\ Rajasthan, India
}

\author{
Dr. S. Srinivasan \\ Professor \\ PDM Engineering College \\ Bhadurgarh 1245 \\ Haryana, India
}

\author{
Dr. Subhra Das \\ Professor \\ Manav Rachna College of Engg. \\ Faridabad 121001 \\ Haryana, India
}

\begin{abstract}
Today supplier selection is a critical and demanding process for the industry, which provides the company with the accurate product/raw material and/or services at the right price at the right time and in the required quantities. Consequently, supplier selection become very important for maintaining planned association. The objective of this paper is to introduce a method of supplier selection based on multiagent and fuzzy decision making techniques include with risk factor for the selection of supplier. The proposed method combines the multi agent technique and fuzzy decision making technique for supplier selection. Finally this integrated model is illustrated by an example in an existing firm to validate the proposed model. By applying the concept of risk factor analysis, ranking values of supplier are converted in final pricing model to set segmented price.
\end{abstract}

\section{Keywords}

Agent, Fuzzy Decision making Techniques and Supply Chain

\section{INTRODUCTION}

The basic objective of all these entities is to offer good quality product at best reasonable price. It has been observed that many methodologies have been applied in literature for the proposed work, which is shown in the fig 1.In the last decade, a lot of changes have been seen in supplier selection process. Many industries are now abandoning the lowest bidder supplier selection methodology of the past instead empowering multidisciplinary sourcing teams to select the best supplier available for each component. Linear Programming (LPP), Mixed Objective Programming (MOP), analytical hierarchy processes are commonly (AHP) are commonly used techniques for the said issue. Earlier works on supplier selection identified 23 criteria (i.e. price, delivery, quality etc.) for evaluating and selecting appropriate supplier and deciding on the size of the order to be placed with each supplier. In 47 out of 76 articles, supplier selection used more than one criterion [Multi-criteria]. One of the well known studies on supplier selection belongs to Dicsons [2006]. The goal of this paper is to study concept, and design system in MAS with a focus on Suppliers Selection Management. Chen, Ching and Sue [1] introduce a hierarchy multiple criteria decision-making (MCDM) model based on fuzzy-sets theoryWhich deal with the supplier selection problems in the supply chain system. For the first time in a fuzzy supplier selection problem, an asymmetric fuzzy-decision making technique is applied to enable the decision-maker to assign different weights to various criteria by the authors Amida, Ghodsypour, and Brien [2]. Florez-Lopez [3] used both quantitative and qualitative data for supplier selection, being its main aim to calculate the ability of the supplier to create value for the customer. Chou and Chang applied a fuzzy SMART to evaluate the alternative suppliers, and deals with the ratings of both qualitative and quantitative criteria. Lin and Chang [4] represent the methods for order selection and pricing of manufacturer (supplier) with make-to-order basis when orders exceed production capacity. Yang, Chiu, Tzeng and Yeh [5] used triangular fuzzy numbers to express the subjective preferences of evaluators and then used interpretive structural modeling (ISM) to map out the relationships among the subcriteria. This is focused by fuzzy analytical hierarchy process (AHP). Faeza, Ghodsypoura and Brien [6] focused on a casebased reasoning (CBR) approach which is a reently recommended method for solving the VSP by making use of previous similar situations. Guneri, Yucel and Ayyildiz [7] presented an integrated fuzzy and linear programming approach to the problem. Önüt, Kara and ik [8] developed a supplier evaluation approach based on the analytic network process (ANP) and the technique for order performance by similarity to ideal solution (TOPSIS) methods to help a telecommunication company in the GSM sector in Turkey under the fuzzy environment. Lee, Kang and Chang [9] developed a fuzzy multiple goal programming (FMGP) model to help downstream companies to select thin film transistor liquid crystal display (TFT-LCD) suppliers for cooperation. Wu [10] employed grey related analysis as a means to reflect uncertainty in multiattribute models through interval numbers. Second, in the group aggregation, the Dempster-Shafer (D-S) rule of combination is used to aggregate individual preferences into a collective preference, by which the candidate alternatives are ranked and the best alternative(s) are obtained. Razmi, Rafiei and Hashemi [11] developed a fuzzy analytic network process (ANP) model to evaluate the potential suppliers and select the best one(s) with respect to the vendor important factors. L.S. Chen, C.H. Cheng, Selecting IS personnel using ranking fuzzy number by metric distance method. Ming-Lang, Chiang and LAN [12] rationales for the evaluation framework are based upon multi-criteria decision making (MCDM) and choquet integral-a non-additive fuzzy integral thatcan eliminate the interactivity of expert subjective judgment problems. Yücel and Güneri [13] handled ambiguity and fuzziness in supplier selection problem effectively; a new weighted additive fuzzy programming 
approach is developed. Sanayei , Mousavi and Yazdankhah [14] proposed a hierarchy MCDM model based on fuzzy sets theory and VIKOR method to deal with the supplier selection problems in the supply chain system. Keskin, Sevinç_Ilhan and Özkan [15] applied Fuzzy Adaptive Resonance Theory (ART)'s classification ability to the supplier evaluation and selection area. lc, o"zkan and GizemC [16] developed a novel approach based on fuzzy analytic network process within multi-person decision-making schema under incomplete preference relations. Amida, Ghodsypour and Brien [17] used an analytic hierarchy process (AHP) to determine the weights of criteria. Wang [18] took advantage of the 2-tuple linguistic computing to cope with the heterogeneity and information loss problems while the evaluation processes of subjective integration. Hsu, Chiang and Shu [19] solved the nonlinear programming problems with bounded variables to construct the membership function of a fuzzy capability-index estimate for each supplier. DíazMadroñero, Peidro and Vasant [20] developed methods for solving multi-objective VS problems where fuzzy data are represented by using S-curve membership functions. Punniyamoorthy, Mathiyalagan and Parthiban [21] developed a new composite model using structural equation modeling and fuzzy analytic hierarchy process technique, based on the results of a survey of 151 respondents Kara [22] proposed an integrated methodology and its solution for supplier selection problem. A two stage stochastic programming model and fuzzy TOPSIS methods are consolidated in this methodology. Zeydan, Çolpan and Çobanog [23] considered both qualitative and quantitative evaluating performance for selection of suppliers based on efficiency and effectiveness in one of the biggest car manufacturing factory in Turkey.

\section{PROPOSED ARCHITECTURE WITH EXPECTED OUTCOMES}

Supply chain management is a huge network in which many entities like supplier, customer, retailer, distributors, warehouses \& factory are included, where supplier selection process is a critical and important part for the smooth function of supply chain. Combination of Software Agent and Fuzzy set theory has been applied to the problem of supplier selection.(Fig. 1) where different agents(Material Information Agent, Supplier Agent, Customer Agent, Quality Agent, Delivery Agent, Services/Technical Agent.) works for different jobs .Each agent collects the information, does grading and pass the information to the overall performance agent. [24]. As the study is concerned, a committee is formed of four decision takers like ( $\mathrm{R} \& \mathrm{D}$ Manager, Purchase Manager, Technical Head and operation Manager) involved in supplier selection procedure from different departments within the company. After the analysis of previous research and data collected from different company (A, Dickson (1966); B, Lehmann \& O'Shaughnessy (1974); C, Abratt (1986); D, Weber, Current, \& Benton (1991); E, Min \& Galle (1999); F, Stavropolous (2000); G, Ghodsypour \& O'Brien (2001); H, Chan \& Kumar (2007); I, Chen et al. (2006); J, Lin \&Chang (2008).),

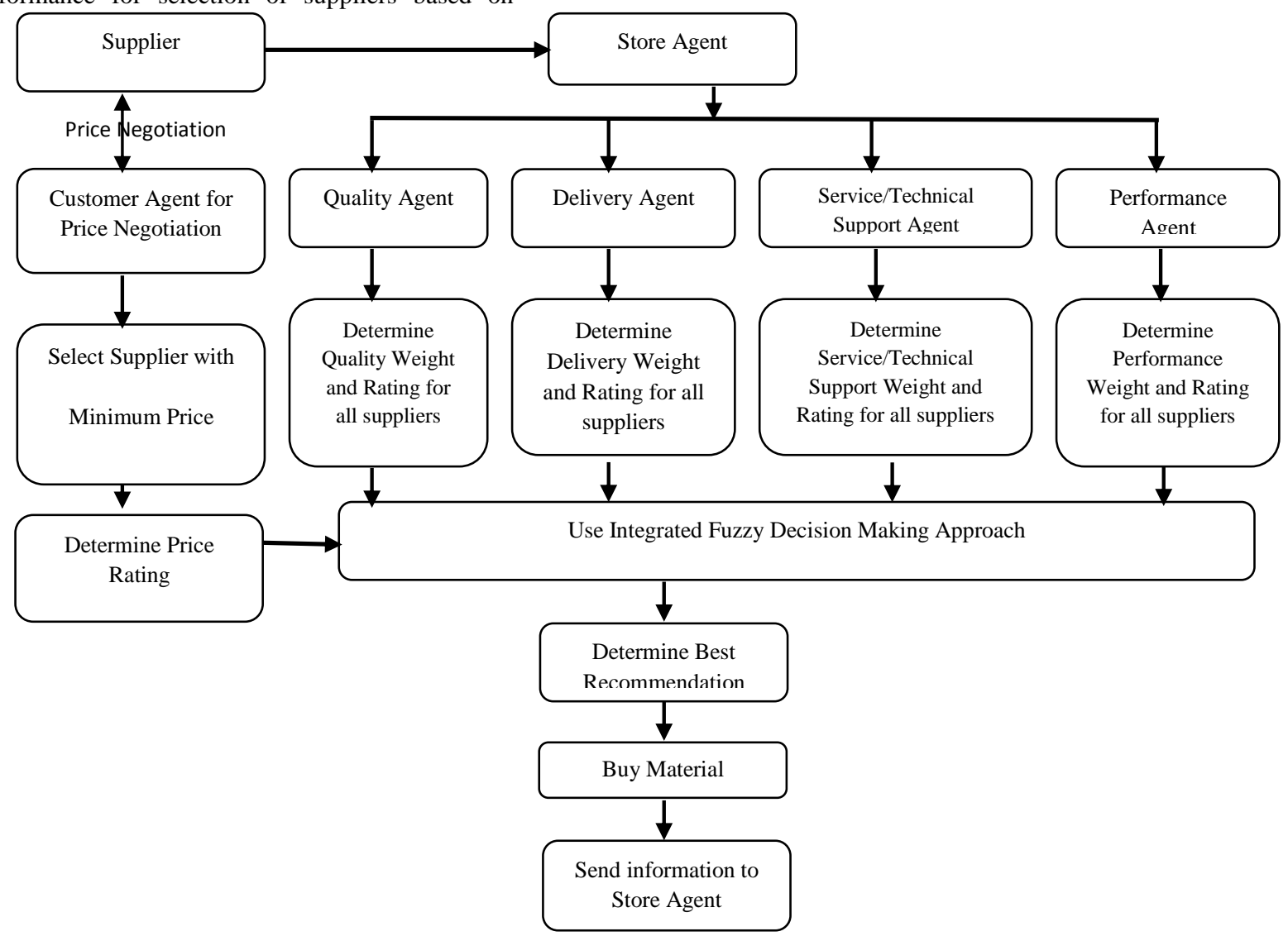

Fig 1: Agent Based Model for supplier Selection 
The five criterions as Price (C1), Quality (C2), Delivery (C3), Services/Technical (C4) and Performance (C5) have been selected for supplier selection. Every decision taker, involved here have different weight in the supplier selection procedure and every supplier have different risk factor which are calculated by the overall past performance and supplier history of company which are as follows: As every decision taker have different significance for the supplier selection process so significance factor $\left(S_{t}\right)$ for $R \& D$ Manager(D1), Purchase Manager(D2), Technical Head(D3) and operation Manager(D4) are 4,6,2,5 and risk factor (Rf) for supplier $A_{1}, A_{2}, A_{3}$ and $A_{4}$ are $.20, .10, .15$ and .15

\subsection{Triangular Fuzzy Number}

Agents use the fuzzy decision making techniques to select the best supplier. Zadeh proposed the fuzzy set theory and introduced the concept of membership function (Zadeh, 1965).The fuzzy set theory deals with linguistic variable problem in real world.

The four decision takers use for linguistic weighting variable to access the importance of the criteria. The importance weight and rating with their relative TFNs. is tabulated in Table 1

Table 1. TFNs of importance Wight and Rating

\begin{tabular}{|c|ccc|c|ccc|}
\hline \multicolumn{3}{|c|}{ Linguistic Variables } & \multicolumn{5}{c|}{ Rating } \\
\hline $\begin{array}{c}\text { Linguistic } \\
\text { Variables }\end{array}$ & \multicolumn{2}{|c|}{ TFNs } & $\begin{array}{c}\text { Linguistic } \\
\text { Variables }\end{array}$ & \multicolumn{3}{c|}{ TFNs } \\
\hline VL & 0 & 0 & 1 & VP & 0 & 10 & 10 \\
L & 0 & 1 & 3 & P & 0 & 10 & 30 \\
ML & 1 & 3 & 5 & MP & 10 & 30 & 50 \\
M & 3 & 5 & 7 & F & 30 & 50 & 70 \\
MH & 5 & 7 & 9 & MG & 50 & 70 & 90 \\
H & 7 & 9 & 10 & G & 70 & 90 & 100 \\
VH & 9 & 10 & 10 & VG & 90 & 100 & 100 \\
\hline
\end{tabular}

Customer initial offer

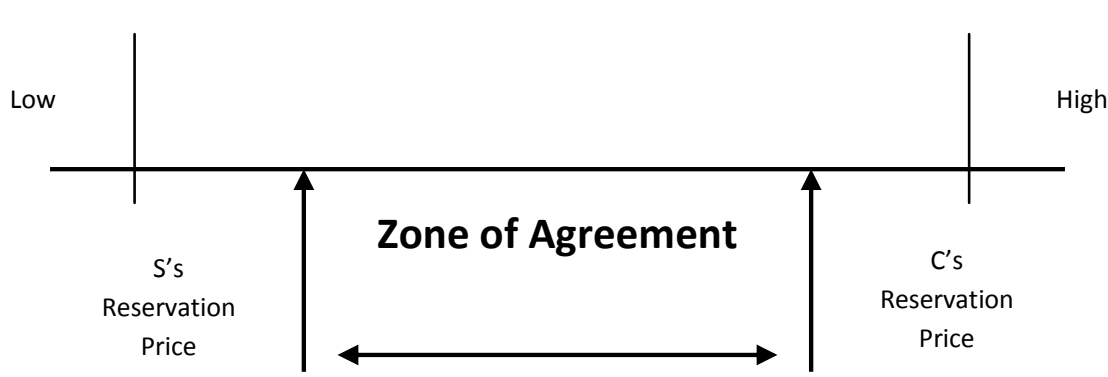

The membership function is defined as

$$
\mu_{A}^{-}(y)=\left\{\begin{array}{cc}
0, & y<a \\
y-\frac{a}{b}-a, & a \leq y \leq b \\
0, & y>c
\end{array}\right\}
$$

For the ease of understanding, proposed algorithm for decision making in supplier selection is as follows

Step 1 Identify Key Supplier evaluation categories say quality, price etc.

Step 2 Calculate weight for categories.

Step 3 Generate weight table.

Step 4 Generate a rating table.

Step 5 In this paper, method has been proposed to generate real data by applying agent Negotiation technique only for price.

Step 6 Integrate fuzzy data and agent negotiation results.

Step 7 Calculates Total fuzzy value and total crisp value by using integrated Fuzzy approach.

Step 8 apply risk factor analysis on the fuzzy rating, Find the best one supplier

Step 9 Apply the model in supplier selection on real data and find out the best one supplier among the suppliers.

Step 10 Ends.

\subsection{Proposed Negotiation Model for Price Selection}

To illustrate the concept, the negotiation process assumes that the relevant information set $\mathrm{X}$ consists only one item, i.e. the belief about a supplier's reservation prices - the threshold of an acceptable offer. The reservation price is typically exclusive to each agent, and the reservation prices of different agents may not be the same. As shown in Fig 3 when the supplier's reservation price (RPs) is lower than that of the customer (RPc), a candidate solution would settle at any point within the "zone of agreement". Within the "zone of agreement", the parties will make concessions from their initial proposals; by which the contactor will increase the initial proposal while the supplier will decrease theirs. Eventually, a proposal that is within the "zone of agreement" and is acceptable to both would be reached for further test criteria. Based on the notion of "zone of agreement', the Product Best Price can be extended to cover the communication level.

Supplier initial offer 
In this extended protocol, 12 actions are introduced, i.e. (i) propose; (ii) accept invitation; (iii) reject; (iv) offer; (v) counteroffer; (vi) reoffer; (vii) concession; (viii) strategic delay; (ix) collision; (x) accept; (xi) deny; and (xii) confirm.

\section{Algorithms for price Negotiation}

Step 1 Invite $(C \rightarrow S)$

Step 2 if Reject $(\mathrm{S} \rightarrow \mathrm{C})$ goto Step1

Step 3 count (n)

$$
\mathrm{n}=1
$$

Step 4 if offer or reoffer $(S \rightarrow C)$

Step 5 if found (ok) goto step 5

Else
$n=n+1$
if $n<=$ agreeable number
goto Step 3
else

Step 5 end (negotiation)

\section{INTEGRATED FUZZY APPROACH FOR OTHER CRITERIA}

\subsection{Fuzzy criteria weight formulation}

$\mathrm{W}_{\mathrm{jp}}=(1, \mathrm{~m}, \mathrm{r}), \mathrm{j}=1,2,3-\mathrm{n}_{\mathrm{N}} \mathrm{n}=1,2,3$----- $\mathrm{k}$ be the linguistic weight give to criteria $C_{j}=1,2,3$----- $n$ by DTs. The combined fuzzy criteria $\mathrm{C}_{\mathrm{j}}$ assessed by committee of $\mathrm{k}$ DTs, as

$$
W_{j}=\left(S_{1} W_{1}+S_{2} W_{2}+----S_{t} W_{t}\right) \div \sum_{t=1}^{k} S_{t} 1
$$

Here, center of gravity method is adopted to defuzzify the criteria weight, which is denoted by

$$
X\left(W_{j}\right)=l_{1}\left[\left(m_{j}-l_{1}\right)+\left(r_{j}-l_{1}\right)\right] \div 3
$$

Crisp value of normalized weight for criteria $\mathrm{Cj}$ represented as $\mathrm{Wj}$

$$
W_{j}=X\left(w_{j}\right) \div \sum_{n}^{j=1} X\left(w_{j}\right)
$$

Agent Negotiation data and normalized fuzzy rating of each suppliers with respect to price criteria:

Let Yijt (lijt mijt rijt); i= 1, 2 --- m, j=1, 2--- h, t=1, 2 ---k, be the linguistic suitability rating assigned to alternative supplier $\mathrm{Ai}$ for price criteria $\mathrm{C} 1$ by the decision taker

$$
Y_{i j t}=\frac{\max _{i}\left\{f_{i j t}\right\}-v_{i j t}}{\max _{i}\left\{f_{i j t}\right\}-\min _{i}\left\{f_{i j t}\right\}} \times 100
$$

Let Yij be the combined fuzzy rating of alternative Ai for criteria $\mathrm{Cj}$ such that

$$
Y_{i j}=S_{t} Y_{i j 1}+S_{2} Y_{i j 2}+---S_{t} Y_{i j k} \div \sum_{t=1}^{k} S_{t} 5
$$

Let us further divide $\mathrm{Xij}$ as the aggregated fuzzy rating of alternative $\mathrm{Ai}$ for criteria $\mathrm{Cj}$ such that

$$
X_{i j}=W_{j} \times Y_{i j}
$$

Where $\mathrm{X}$ (lij, mij, rij) is the combination of the total fuzzy values of individual alternatives

$$
\mathrm{T}=\mathrm{D} \times \mathrm{W}^{\mathrm{T}}
$$

Where

T- Total fuzzy value

D- Rating Matrix

Defuzzification of total fuzzy values having with risk factor (Rf) of individual suppliers

$$
\begin{aligned}
& \mathrm{d}\left(\mathrm{f}_{\mathrm{i}}\right)=\mathrm{R}_{\mathrm{f}} * \mathrm{l}_{\mathrm{i}}+\left(\mathrm{l}_{\mathrm{i}-} \mathrm{r}_{\mathrm{i}}\right)^{*} \mathrm{r}_{\mathrm{i}} \\
& 0 \leq \mathrm{ri} \leq 1 \\
& \text { Where fi (li, mi, ri) }
\end{aligned}
$$

\subsection{Numerical Example}

Industry GB (industry) is a famous manufacturer, and is a leader in fabrication equipment like refineries, petrochemical, fertilizers, oil \& gas chemicals and power around the world. Based on these practical focuses on the process equipment for the analysis, four potential suppliers are taken. The proposed methodology for supplier selection in this paper is as follows:

Step1 Firstly, as study is concerned, committee is formed of four decision takers from different department within the company who is related to supplier selection.

After the analysis of previous research and data collected from different company(A, Dickson (1966); B, Lehmann \& O'Shaughnessy (1974); C, Abratt (1986); D, Weber,Current, \& Benton (1991); E, Min \& Galle (1999); F, Stavropolous (2000); G,Ghodsypour \& O'Brien (2001); H, Chan \& Kumar (2007); I, Chen et al. (2006); J, Lin \&Chang (2008).), choose five criteria. 
And after the analysis from the GBs Data, significance weight of individual DTs $\mathrm{St}\left(\mathrm{S}_{1=} 4, \mathrm{~S}_{2=} 6, \mathrm{~S}_{3=} 2, \mathrm{~S}_{4=} 5\right)$ are assigned.

Step 2 Four decision takers use the linguistic weighting variable to access the importance of the criteria. The importance weight and rating with their relative TFNs. (Table 1)

Step 3 Find out the linguistic and aggregated fuzzy weight of the criteria by eqn (1). (Table 2 )

Table 2. Linguistic and aggregated importance of the criteria

\begin{tabular}{|c|c|c|c|c|c|c|c|c|c|}
\hline \multirow{3}{*}{ 岂 } & \multicolumn{2}{|c|}{$\begin{array}{l}\text { DM's } \\
\text { Weights }\end{array}$} & \multicolumn{2}{|c|}{ Linguistic } & \multicolumn{5}{|c|}{ Aggregated Weight } \\
\hline & \multirow[t]{2}{*}{ D1 } & \multirow[t]{2}{*}{ D2 } & \multirow[t]{2}{*}{ D3 } & \multirow[t]{2}{*}{ D4 } & \multicolumn{3}{|c|}{ Fuzzy Rating } & \multirow{2}{*}{$\begin{array}{l}\text { Defuzzi } \\
\text { Fied } \\
\mathbf{X}(\mathbf{W j})\end{array}$} & \multirow{2}{*}{$\begin{array}{l}\text { Norma } \\
\text { lized } \\
\text { (Wj) }\end{array}$} \\
\hline & & & & & 1 & $\mathrm{~m}$ & $\mathrm{r}$ & & \\
\hline $\mathrm{C} 1$ & $\mathrm{M}$ & $\mathrm{L}$ & $\mathrm{L}$ & $\mathrm{L}$ & .75 & 1.94 & 3.94 & 2.20 & .10 \\
\hline $\mathrm{C} 2$ & $\mathrm{M}$ & $\mathrm{VH}$ & $\mathrm{VH}$ & $\mathrm{M}$ & 5.82 & 7.35 & 8.41 & 7.20 & .32 \\
\hline $\mathrm{C} 3$ & M & M & $\mathrm{M}$ & M & 3.00 & 5.00 & 7.00 & 5.00 & .22 \\
\hline $\mathrm{C} 4$ & M & M & M & M & 3.00 & 5.00 & 7.00 & 5.00 & .22 \\
\hline $\mathrm{C} 5$ & M & $\mathrm{L}$ & $\mathrm{L}$ & M & 1.59 & 3.12 & 5.12 & 3.27 & .14 \\
\hline
\end{tabular}

Step 4 By using center of gravity method, find out the difuzzified values of aggregated weight by eqn (2) (Table 2)

Table 3 Total Fuzzy and TVC

\begin{tabular}{|c|c|c|c|c|c|c|c|c|}
\hline \multirow{2}{*}{$\begin{array}{l}\text { Crit } \\
\text {-eria }\end{array}$} & \multirow{2}{*}{$\begin{array}{c}\text { Suppl } \\
\text { iers }\end{array}$} & \multicolumn{4}{|c|}{ DM's Linguistic Weights } & \multicolumn{3}{|c|}{$\begin{array}{c}\text { Aggregated Fuzzy } \\
\text { Rating }\end{array}$} \\
\hline & & D1 & D2 & D3 & D4 & 1 & $\mathbf{m}$ & $\mathbf{r}$ \\
\hline \multirow{4}{*}{$\mathrm{C} 2$} & $\mathrm{~S} 1$ & G & VG & VG & G & 79.41 & 94.71 & 100 \\
\hline & S2 & MG & VG & VG & G & 74.71 & 90.00 & 97.65 \\
\hline & S3 & MG & $\mathrm{VG}$ & $\mathrm{VG}$ & G & 74.71 & 90.00 & 97.65 \\
\hline & S4 & MG & VG & VG & G & 42.94 & 50.59 & 52.94 \\
\hline \multirow{4}{*}{$\mathrm{C} 3$} & S1 & G & VG & $\mathrm{F}$ & G & 72.35 & 88.82 & 96.47 \\
\hline & S2 & MG & VG & $\mathrm{F}$ & G & 67.65 & 84.12 & 94.12 \\
\hline & S3 & $\mathrm{F}$ & $\mathrm{G}$ & $\mathrm{F}$ & $\mathrm{F}$ & 44.12 & 64.12 & 80.59 \\
\hline & S4 & $\mathrm{F}$ & MG & $\mathrm{F}$ & $\mathrm{F}$ & 37.06 & 57.06 & 77.06 \\
\hline \multirow{4}{*}{$\mathrm{C} 4$} & S1 & $\mathrm{F}$ & $\mathrm{F}$ & MG & MG & 38.24 & 58.24 & 78.24 \\
\hline & S2 & MG & $\mathrm{F}$ & MG & MG & 42.94 & 62.94 & 82.94 \\
\hline & S3 & MG & $\mathrm{F}$ & MG & MG & 42.94 & 62.94 & 82.94 \\
\hline & S4 & MG & $\mathrm{F}$ & MG & MG & 42.94 & 62.94 & 82.94 \\
\hline \multirow{3}{*}{ C5 } & S1 & $\mathrm{F}$ & $\mathrm{F}$ & $\mathrm{F}$ & $F$ & 30.00 & 50.00 & 70.00 \\
\hline & S2 & $\mathrm{MG}$ & $\mathrm{F}$ & $\mathrm{F}$ & $\mathrm{F}$ & 34.71 & 54.71 & 74.71 \\
\hline & S3 & $\mathrm{F}$ & $\mathrm{F}$ & $\mathrm{F}$ & $F$ & 30.00 & 50.00 & 70.00 \\
\hline
\end{tabular}

\begin{tabular}{|c|c|c|c|c|c|c|c|c|}
\hline & S4 & F & F & F & F & 30.00 & 50.00 & 70.00 \\
\hline
\end{tabular}

Step 5 Normalize the difuzzified values by using eqn (3)

Step 6 Calculate the Aggregated fuzzy rating

Step 7 Now by using the said algorithms that is "Agent negotiation algorithm for price", find out the real data (arbitrary Data) for the price for all suppliers say $60 \%$ for S1 $70 \%$ for S2, $30 \%$ for S3 and $50 \%$ for S4. (Table 4)

Step 8 In accordance with price negotiation data, the normalized values of individual quantitative criteria can be eqn (4)

Table 4 Real Data and Normalized Fuzzy Rating (NFRs) of each supplier with respect to all quantitative criteria for each cost

\begin{tabular}{|c|c|c|c|c|c|}
\hline \multirow{3}{*}{ Criteria } & \multirow{2}{*}{ Suppliers } & \multirow{2}{*}{$\begin{array}{c}\text { Real } \\
\text { Data (\%) }\end{array}$} & \multicolumn{3}{|c|}{ NFRs } \\
\cline { 4 - 6 } & & & Y & Y & Y \\
\hline \multirow{3}{*}{ C1 } & S1 & 60 & 25 & 25 & 25 \\
\cline { 2 - 6 } & S2 & 70 & 0 & 0 & 0 \\
\cline { 2 - 6 } & S3 & 30 & 100 & 100 & 100 \\
\cline { 2 - 6 } & S4 & 50 & 50 & 50 & 50 \\
\hline
\end{tabular}

Step 9 Find out the linguistic and aggregated fuzzy rating of criteria by eq ${ }^{\mathrm{n}}(5)$. (Table 4)

\section{Table 5. Fuzzy Rating Matrix}

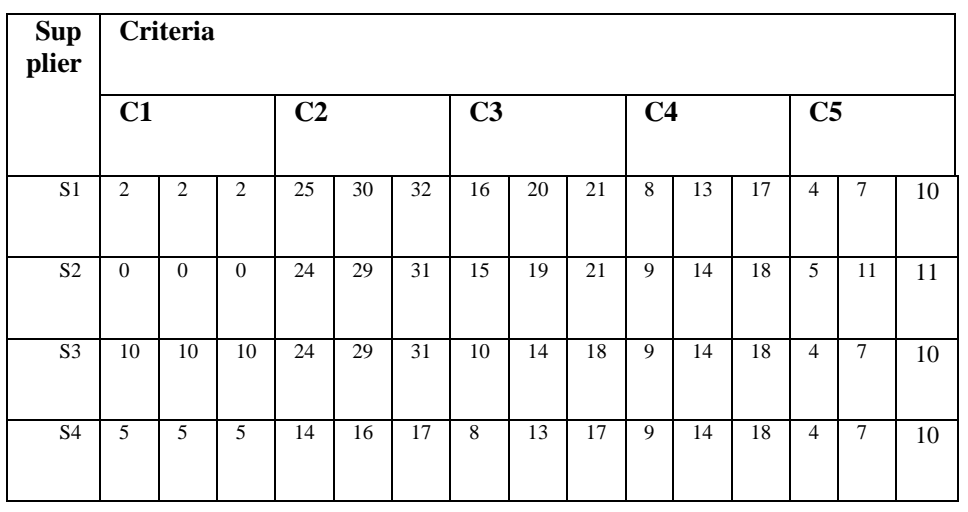

Step 9 Find out the difuzzified values of aggregated weight by using eq ${ }^{\mathrm{n}}(5)$. (Table 5)

Step 10 Find out total fuzzy values of individual supplier by equation 7. (Table 6) and then calculate the total the TVC and at last make a ranking order table. by can say that A1 and A2 supplier should be the business partner of the company.

Table 6. Total Fuzzy and TVC

\begin{tabular}{|c|c|c|c|c|c|}
\hline \multirow{2}{*}{$\begin{array}{c}\text { Supplie } \\
\mathbf{r}\end{array}$} & \multicolumn{3}{|c|}{ Fuzzy Value (T) } & \multirow{2}{*}{ TVC } & $\begin{array}{c}\text { Risk } \\
\text { Coefficien } \\
\mathbf{t}\end{array}$ \\
\cline { 2 - 5 } & $\mathbf{l}$ & $\mathbf{m}$ & $\mathbf{r}$ & & 020 \\
\hline $\mathrm{A} 1$ & $\begin{array}{c}14.2457893 \\
6\end{array}$ & $\begin{array}{c}17.9 \\
8\end{array}$ & $\begin{array}{c}20.2 \\
8\end{array}$ & $\begin{array}{c}19.0 \\
7\end{array}$ & 020 \\
\hline $\mathrm{A} 2$ & $\begin{array}{c}9.89178619 \\
7\end{array}$ & 12.4 & $\begin{array}{c}14.0 \\
6\end{array}$ & $\begin{array}{c}13.6 \\
4\end{array}$ & 0.10 \\
\hline
\end{tabular}




\begin{tabular}{|c|c|c|c|c|c|}
\hline A3 & $\begin{array}{c}8.77481411 \\
9\end{array}$ & $\begin{array}{c}10.4 \\
8\end{array}$ & $\begin{array}{c}11.5 \\
4\end{array}$ & $\begin{array}{c}11.1 \\
3\end{array}$ & 0.15 \\
\hline A4 & $\begin{array}{c}3.03802469 \\
2\end{array}$ & $\begin{array}{c}3.38 \\
9\end{array}$ & $\begin{array}{c}3.49 \\
7\end{array}$ & 3.43 & 0.15 \\
\hline
\end{tabular}

\section{RESULTS ANALYSIS}

This study uses the fuzzy and agent technology to analyze Auto industry suppliers and empirical study identifies the best supplier as A1.The TCVs of supplier A2 and supplier A3 are close, with the TCV of supplier A2 being 13.64 and that of supplier A3 being 11.13 (Table 6). By analyzing the ranking order table, can say that A1 supplier should be the business partner of the company.

\section{CONCLUSION}

So we can say that if we want to build a long term and closeness relationships between customer and supplier is a critical task in the success of supply chain management. To achieve this goal, decision makers should apply best method and select proper criteria for the supplier selection problem. Within this research, we try to build an effective model not only considers decision makers experience for supplier selection criteria, but also includes various constraints. Agent technology gives us the best price (Min Price) after the negotiation between the customer and suppliers. And fuzzy set

\section{ACKNOWLEDGMENTS}

Our very thanks to the experts who have contributed towards development of the template.

\section{REFERENCES}

[1] Amida, A. , Ghodsypour, S.H., Brien, C.O’. (2006). Fuzzy multi-objective linear model for supplier selection in a supply chain. Int. J. Production Economics, 104 394-407

[2]Chou, S.Y. and Chang, Y.H. (2008) A decision support system for supplier selection based on a strategy-aligned fuzzy SMART approach. Expert Systems with Applications, 34 2241-2253

[3] Florez, R. (2007) Strategic supplier selection in the addedvalue perspective: A CI approach. Information Sciences, $177 \quad 1169-1179$

[4] Lin, H.T. and Chang, W.T. (2008). Order selection and pricing methods using flexible quantity and fuzzy approach for buyer evaluation. European Journal of Operational Research, 187 (2008) 415-428

[5] Yang, J.L., Chiu, H.N. and Yeh, G.H.T.R.H. (2008). Vendor selection by integrated fuzzy MCDM techniques with independent and interdependent relationships. Information Sciences, 178 (2008) 4166-4183

[6]Faeza, F., Ghodsypoura, S.H. and Brien, C.O. (2009). Vendor selection and order allocation using an integrated fuzzy case-based reasoning and mathematical programming model. Int. J. Production Economics, 121(2009)395-408

[7] Guneri, A. F., Yucel, A., Ayyildiz, G. (2009). An integrated fuzzy-lp approach for a supplier selection problem in supply chain management. Expert Systems with Applications, 36 (2009) 9223-9228

[8] Önüt, S. ,Kara,S.S., and ik, E.I. (2009). Long term supplier selection using a combined fuzzy MCDM approach: A case study for a telecommunication company. Expert Systems with Applications, 36 (2009) 3887-3895

[9] Lee, A.H.I., Kang, H.Y., Chang, C.T. (2009). Fuzzy multiple goal programming applied to TFT-LCD supplier selection by downstream manufacturers. Expert Systems with Applications, 36 (2009) 6318-6325

[10] Wu, D. (2009). Supplier selection in a fuzzy group setting: A method using grey related analysis and Dempster-Shafer theory. Expert Systems with Applications, 36 (2009) 8892-8899

[11] Razmi, J., Rafiei,H., Hashemi, M. (2009). Designing a decision support system to evaluate and select suppliers using fuzzy analytic network process. Computers \& Industrial Engineering, 57 (2009) 1282-1290

[12] Ming-Lang,T., Chiang, J.H. and Lan, L.W. (2009). Selection of optimal supplier in supply chain management strategy with analytic network process and choquet integral. Computers \& Industrial Engineering, 57 (2009) $330-340$

[13] Yücel, A. and Güneri, A.F. (2010). A weighted additive fuzzy programming approach for multi-criteria supplier selection. Expert Systems with Applications, xxx (2010)

[14] Sanayei, A., Mousavi S.F., Yazdankhah A. (2010). Group decision making process for supplier selection with VIKOR under fuzzy environment. Expert Systems with Applications, 37 (2010) 24-30

[15] Keskin,G.E.A., Sevinç_Ilhan and Özkan, C.K. (2010). The Fuzzy ART algorithm: A categorization method for supplier Evaluation and selection. Expert Systems with Applications, 37 (2010) 1235-1240

[16] lc, G. skan,.I, GizemC, ifc and I (2010). A novelfuzzymul ti - criteria decision framework for sustainable supplier selection with in complete information Computers in Industry $\operatorname{xxx}(2010)$

[17] Amida, A. , Ghodsypour, S.H., Brien, C.O'. (2010). A weightedmax-min model for fuzzy multi-objective supplier Selection in a supply chain. Int. J.Production Economics

[18] Wanga,J.W., Cheng, C.H. and Cheng, H.K. (2009). Fuzzy hierarchical TOPSIS for supplier selection Applied Soft Computing, 9 (2009) 377-386

[19] Hsu, B.M., Chiang, C.Y. and Shu, H.W. (2010). Supplier selection using fuzzy quality data and their applications to touch screen. Expert Systems with Applications, 37 (2010) 6192-6200

[20] Díaz-Madroñero ,M., Peidro, D., Vasant, P. (2010). Vendor selection problem by using an interactive fuzzy multi-objective approach with modified S-curve membership functions. Computers and Mathematics with Applications, 60 (2010) 10381048 
[24] Wang, W.P. (2010). A fuzzy linguistic computing approach to supplier evaluation. Applied Mathematical Modelling, 34 (2010) 3130-3141

[21] Punniyamoorthy,M., Mathiyalagan, P., Parthiban, P. (2011). A strategic model using structural equation modeling and fuzzy logic in supplier selection. Expert Systems with Applications, 38 (2011) 458-474
[22] Kara, S.S. (2011). Supplier selection with an integrated methodology in unknown environment. Expert Systems with Applications, 38 (2011) 2133-2139

[23] Zeydan, M.,Çolpan, C. and Çobanog, C. (2011). A combined methodology for supplier selection and performance evaluation. Expert Systems with Applications, 38 (2011) 2741-2751 